\title{
A Heuristic Ranking Approach on Capacity Benefit Margin Determination Using Pareto-Based Evolutionary Programming Technique
}

\author{
Muhammad Murtadha Othman, ${ }^{1,2}$ Nurulazmi Abd Rahman, ${ }^{3}$ Ismail Musirin,, ${ }^{1,2}$ \\ Mahmud Fotuhi-Firuzabad, ${ }^{4}$ and Abbas Rajabi-Ghahnavieh ${ }^{5}$ \\ ${ }^{1}$ Committee of Research (CORE), Advanced Computing \& Communication (ACC), Universiti Teknologi MARA, \\ 40450 Shah Alam, Selangor, Malaysia \\ ${ }^{2}$ Faculty of Electrical Engineering, Universiti Teknologi MARA, 40450 Shah Alam, Selangor, Malaysia \\ ${ }^{3}$ Engineering Centre, University Malaysia Perlis, Kampus Kubang Gajah, 02600 Arau, Perlis, Malaysia \\ ${ }^{4}$ Centre of Excellence in Power System Management and Control, Electrical Engineering Department, Sharif University of Technology, \\ Tehran 11365-11155, Iran \\ ${ }^{5}$ Department of Energy Engineering, Sharif University of Technology, Tehran 11365-11155, Iran
}

Correspondence should be addressed to Muhammad Murtadha Othman; mamat505my@yahoo.com

Received 6 May 2014; Accepted 15 September 2014

Academic Editor: Shifei Ding

Copyright (C) 2015 Muhammad Murtadha Othman et al. This is an open access article distributed under the Creative Commons Attribution License, which permits unrestricted use, distribution, and reproduction in any medium, provided the original work is properly cited.

\begin{abstract}
This paper introduces a novel multiobjective approach for capacity benefit margin (CBM) assessment taking into account tie-line reliability of interconnected systems. CBM is the imperative information utilized as a reference by the load-serving entities (LSE) to estimate a certain margin of transfer capability so that a reliable access to generation through interconnected system could be attained. A new Pareto-based evolutionary programming (EP) technique is used to perform a simultaneous determination of CBM for all areas of the interconnected system. The selection of CBM at the Pareto optimal front is proposed to be performed by referring to a heuristic ranking index that takes into account system loss of load expectation (LOLE) in various conditions. Eventually, the power transfer based available transfer capability (ATC) is determined by considering the firm and nonfirm transfers of CBM. A comprehensive set of numerical studies are conducted on the modified IEEE-RTS79 and the performance of the proposed method is numerically investigated in detail. The main advantage of the proposed technique is in terms of flexibility offered to an independent system operator in selecting an appropriate solution of CBM simultaneously for all areas.
\end{abstract}

\section{Introduction}

In a deregulated power system environment, electricity is considered as a commodity that can be traded in a free market where the generators and loads participated. The transition to a new structure of electricity market is to ensure the quality and efficient production of electrical energy that can be offered at a lower electricity price as well as maximizing the utilization of generation and transmission facilities $[1,2]$. Hence, it is important for the independent system operator (ISO) to calculate and provide the information of available transfer capability (ATC) associated with the transfer paths to the open access same-time information system (OASIS) so that electricity market could be conducted in an effective manner $[3,4]$. ATC is defined as the maximum amount of power that can be transferred from a selling area to a buying area without jeopardizing a system security [5]. ATC can be calculated as the total transfer capability (TTC) reduced by the transmission reliability margin (TRM), capacity benefit margin (CBM), and existing transmission commitment (ETC). CBM is one of the main components considered in the ATC calculation and is defined as the amount of transfer capability reserved by load-serving entities, which is anticipated to be used in cases of generation deficiency [5-9]. 
Inaccurate determination of CBM may result in either underestimation or overestimation of the ATC. Underestimating the ATC value possibility will cause an ineffective use in the transmission facility, while overestimating the ATC value will threaten a power system security $[3,7]$.

So far, several methods have been proposed to determine CBM [10-19]. The basic method used to compute the CBM for each area of an interconnected system is based on trial and error [10], by prescribing $5 \%$ of the maximum transfer capability [11] or the CBM value is specified as zero [12, 13]. Reference [14] has proposed an analytic model used for multiarea generation reliability assessment and then applied into the sequential quadratic programming (SQP) for determining the CBM values considering the loss of load expectation (LOLE) as the system reliability criterion. Rajathy et al. [15] use the differential evolution and Monte Carlo techniques to determine the CBM. A method that has been proposed in [16] is used to determine the CBM for each area of an interconnected system using the evolutionary programming (EP) as an accelerated search technique. Furthermore, CBM determination is formulated as an optimization problem which is solved by using the particle swarm optimization (PSO) technique $[17,18]$. In order to provide a set of choices for different cases, three methods have been proposed in $[17,18]$ which will provide different values of CBM. It is observed that the existing CBM calculations do not provide adequate flexibility for the ISO to select a CBM value in accordance with system requirements [10-19]. In addition, tie-line availability is an influential factor which has an effect on the reliability of an interconnected system followed by the value of CBM. This imperative factor has been taken into account for CBM calculation in [19].

A novel multiobjective based optimization approach is presented in this paper to determine several optimum values of CBM using the Pareto-based EP technique that takes into account the tie-line reliability of an interconnected system. The proposed Pareto-based EP technique has several advantages compared to the methodology previously presented in [16] and it provides the ISO with several choices of optimum CBM values. The multiobjective function of EP technique is referred to as the transfer capability margin of CBM for all areas with LOLE less than a specified value at initial condition. Moreover, the CBMs of all areas are obtained simultaneously at every execution of the proposed technique. The first order sensitivity with modified Gaussian formulation is used as a new mutation technique to enhance the EP performance in searching for a new population at global maximum domain with less computational time. Then, the Pareto optimal front approach is used to select several optimal solutions of CBM values using the ranking index of total LOLE and total difference of LOLE. A modified IEEERTS79 is used as the numerical test bed to verify effectiveness of the proposed method in providing the solutions of CBMs [17]. The robustness of the proposed method in CBM determination is compared with that of the basic methodology used for the CBM calculation [17]. Performance comparison has also been performed which investigates the effect of tieline reliability included in the CBM determination. Finally, the significance of CBM considered as firm and nonfirm transfers can be observed through its impact on the ATC determination.

\section{Multiobjective Functions of Capacity Benefit Margins Determination}

A process involved in the Pareto-based EP technique used for determining the multiobjective function of CBMs is described as follows.

Step (a). Establish a solved base case power flow solution.

Step (b). Determine the LOLE for each area of the interconnected system at the base case condition.

Step (c). Identify the assisting areas with LOLE less than the specified value, $\xi$ (e.g., $2.4 \mathrm{hrs} / \mathrm{yr}$ ). It signifies that these areas conserve a certain amount of reserve generating capacity that could be used to compensate for the generation deficiency which may occur in the assisted area. LOLE associated with the assisted area is usually greater than $\xi$. It is important to mention that the assisting and assisted areas are the terms used to signify the direction of power transfer based CBM $\left(\mathrm{CBM}_{\mathrm{asg}}^{\text {Pareto }}\right)$ and this is different from the selling and buying areas which are the terms used to signify the direction of power transfer based ATC.

Step (d). Identify the assisted area with the largest LOLE above $\xi$.

Step (e). Determine the parent or initial population for each assisting area with LOLE below $\xi$. Equation (1) is used to generate the individuals $x$ par $_{m \text {,asg }}$, for parent or initial population using uniform random distribution. The determination of $x$ par $_{m \text {,asg }}$ is based on either total rating of all tie-lines connecting between the assisting and assisted areas, PLIt ${ }_{\text {asg }}$, or the total reserve generating capacity of the assisting area, $\mathrm{DPGt}_{\mathrm{asg}}$. The $x \mathrm{par}_{m \text {,asg }}$ is determined based on the former condition when DPGt ${ }_{\text {asg }}$ exceeds the PLIt ${ }_{\text {asg }}$. This means that tie-lines are the constraining factors for power transfer based CBM and, thus, $x$ par $_{m \text {,asg }}$ are generated randomly based on PLIt $_{\text {asg }}$. The latter condition is used to determine $x \operatorname{par}_{m \text {,asg }}$ when DPGt $\mathrm{asg}_{\text {as }}$ is less than PLIt ${ }_{\mathrm{asg}}$. Each individual, $x$ par, is considered as an external generating capacity, $\mathrm{PG}_{\mathrm{Ext}}$, or CBM, which is provided by the assisting area to support generating capacity deficiency in the assisted area having the highest LOLE:

$$
x \operatorname{par}_{m, \mathrm{asg}}= \begin{cases}\operatorname{rand}_{m}\left(\mathrm{DPGt}_{\mathrm{asg}}\right), & \text { if } \mathrm{DPGt}_{\mathrm{asg}}<\mathrm{PLIt}_{\mathrm{asg}}, \\ \operatorname{rand}_{m}\left(\mathrm{PLIt}_{\mathrm{asg}}\right), & \text { if } \mathrm{DPGt}_{\mathrm{asg}}>\mathrm{PLIt}_{\mathrm{asg}},\end{cases}
$$

where

$$
\begin{aligned}
\mathrm{DPGt}_{\mathrm{asg}} & =\mathrm{PGt}_{\mathrm{asg}}-\mathrm{PLt}_{\mathrm{asg}}, \\
\mathrm{PLIt}_{\mathrm{asg}} & =\sum_{l=1}^{L} \mathrm{PLI}_{l}^{\mathrm{asg}} .
\end{aligned}
$$

$\mathrm{CBM}_{m \text {,asg }}$ or $x$ par $_{m \text {,asg }}$ is the CBM in the case of transfer from assisting area to assisted area; PGt is the total generating 
capacity; PLt is the total peak load; PLI is the tie-line rating; $L$ is the total number of tie-lines; $m$ is $1,2,3, \ldots$, pop; asg is $1,2,3, \ldots, N a s g$; pop is the population size; and Nasg is the total number of assisting areas.

Step (f). Calculate a new total generation capacity, new $\mathrm{PGt}_{m \text {,asg }}$, for each assisting area according to CBM or $x \operatorname{par}_{m \text {,asg }}$ as given in (3) and (4). The generating capacity of the assisting area is reduced as it is partially assigned to the assisted area. The new generating capacity for each bus $g$ of the assisting area new $\mathrm{PGt}_{m \text {,asg }}$ is obtained based on the ratio of generating capacity as

$$
\text { new } \mathrm{PGt}_{m, \text { asg }}=\sum_{g=1}^{\mathrm{NG}} \text { new } \mathrm{PG}_{g}^{m, \text { asg }}
$$

where

$$
\text { new } \mathrm{PG}_{g}^{m, \text { asg }}=\mathrm{PG}_{g}^{\text {asg }}-\frac{\mathrm{PG}_{g}^{\text {asg }}}{\sum_{g=1}^{\mathrm{NG}} \mathrm{PG}_{g}^{\text {asg }}} \times x \text { par }_{m, \text { asg }} .
$$

PG is the generating capacity and NG is the total number of generator buses.

Step (g). Determine the LOLE for each assisting area $\left(\mathrm{LOLE}_{m \text {,asg }}\right.$ ) considering the new PGt ${ }_{m \text {,asg }}$, hourly peak load, and cumulative probability of generation capacity outage $\left(\mathrm{PC}\left(C_{s}\right)\right)$ as discussed in [19].

Step (h). Determine a new total generation capacity, new $\mathrm{PGt}_{m \text {,asd }=1}$, for an assisted area with the largest LOLE above $\xi$ using (5) and (6). In (6), apportionment of the total $x$ par $_{m \text {,asg }}$ or total $\mathrm{CBM}_{m \text {,asg }}$ to each generator is performed based on the ratio of generating capacity and total generating capacity of an assisted area. For an assisted area, there are pop number of individuals for the size of new total generating capacity, new $\mathrm{PGt}_{m, \text { asd }=1}$,

$$
\text { new } \mathrm{PGt}_{m, \text { asd }=1}=\sum_{g=1}^{\mathrm{NG}} \text { new } \mathrm{PG}_{g}^{m, \text { asd }=1}
$$

where

$$
\text { new } \mathrm{PG}_{g}^{m, \text { asd }=1}=\mathrm{PG}_{g}^{\mathrm{asd}=1}+\frac{\mathrm{PG}_{\mathcal{g}}^{\mathrm{asd}=1}}{\sum_{g=1}^{\mathrm{NG}} \mathrm{PG}_{g}^{\mathrm{asd}=1}} \sum_{\text {asg=1 }}^{\text {Nasg }} x \mathrm{par}_{m, \text { asg }},
$$

where asd is the number of assisted areas, 1 .

Step (i). Calculate the fitness value $\left(f_{m}\right)$, that is, $\operatorname{LOLE}_{m \text {,asd=1 }}$ as discussed in [19]. $f_{m}$ is an important parameter used to assist the determination of a new $x \mathrm{par}_{m \text {,asg }}$ and the convergence criteria for the optimization process. This will be explained thoroughly in the following steps. $f_{m}$ or LOLE $_{m, \text { asd }=1}$ is calculated by taking into account the increased amount of new $\mathrm{PGt}_{m \text {,asd=1 }}$ obtained in Step (h).

Step (j). Perform the mutation to obtain an offspring for each assisting area with LOLE less than $\xi$. In the proposed mutation approach, the modified Gaussian technique is used to improve the capability of global maximum search of a new population with less computational time [16]. This technique is suitable in solving the optimization problems in which considerable discrepancy does exist among the individual values. Each offspring comprising new individuals, $x$ off $_{m \text {,asg }}$, is originated from $x \mathrm{par}_{m \text {,asg }}$. The new individuals, $x \mathrm{off}_{m \text {,asg }}$, are obtained using a new mutation technique that incorporates the first order sensitivity, $\partial x \operatorname{par}_{\text {asg }} / \partial N(f, \xi, \sigma)$, and the modified Gaussian formulation, $N\left(f_{m}, \xi, \sigma\right)$, as expressed in (7). The value of $x$ off $_{m \text {,asg }}$ is varied in accordance with the changes in $f_{m}$ to the estimated LOLE limit, $\xi$. Consider

$$
x \mathrm{off}_{m, \mathrm{asg}}=x \operatorname{par}_{m, \mathrm{asg}}+\left(\left|\frac{\partial x \mathrm{par}_{\text {asg }}}{\partial N(f, \xi \cdot \sigma)}\right|\left(1-N\left(f_{m}, \xi, \sigma\right)\right)\right) \text {, }
$$

where

$$
\begin{gathered}
\frac{\partial x \operatorname{par}_{\mathrm{asg}}}{\partial N(f, \xi, \sigma)}=\frac{\max x \mathrm{par}_{\mathrm{asg}}-\min x \mathrm{par}_{\mathrm{asg}}}{\max N(f, \xi, \sigma)-\min N(f, \xi, \sigma)}, \\
N\left(f_{m}, \xi, \sigma\right)=e^{\left(-\left(f_{m}-\xi\right)^{2} / 2 \sigma^{2}\right)},
\end{gathered}
$$

where max $x$ par $_{\text {asg }}$ and min $x$ parasg $_{\text {asg }}$ are the maximum and minimum values of $x$ par $_{m \text {,asg }}$ for every assisting area, respectively; $\max N(f, \xi, \sigma)$ and $\min N(f, \xi, \sigma)$ are the maximum and minimum values of $N\left(f_{m}, \xi, \sigma\right)$, respectively; and $\sigma$ or $f_{\max }$ is the maximum value of fitness, $f_{m}$ or LOLE m,asd=1 $_{\text {. }}$.

The first order sensitivity is used to overcome the impediment of local maxima or minima which normally occurs in the case of large $f_{m}$. Hence, robustness in searching for the global maxima or minima can easily be guaranteed by using the new mutation technique.

Step (k). Perform Steps (h) and (i) to determine $f_{m}$ or $\mathrm{LOLE}_{m \text {,asd=1 }}$ in relation to a new value of new PGt ${ }_{m \text {,asd=1 }}$ obtained according to (5) considering $x_{\text {off }}$,asg. This implies that the $x_{\text {par }}$,asg in (6) has been replaced by $x$ off $_{m \text {,asg' }}$, yielding to a new value of new $\mathrm{PGt}_{m, \text { asd }=1}$. Apart from the new $\mathrm{PGt}_{m \text {,asd=1 }}$ obtained based on $x \mathrm{off}_{m \text {,asg }}$, determination of $\mathrm{LOLE}_{m, \mathrm{asd}=1}$ also requires several other parameters such as the hourly peak load and new cumulative probability of the generation capacity outage $\left(\mathrm{PC}\left(C_{s}\right)\right)$ as discussed in [19].

Step (l). Perform pairwise comparison to determine the next generation of population comprising the best individuals selected from $x$ off $_{m \text {,asg }}$ and $x$ par $_{m \text {,asg }}$. For each assisting area, $f_{m}$ or $\operatorname{LOLE}_{m, \text { asd }=1}$ has been used as a reference for selecting the best individuals as the next generation of $x \operatorname{par}_{m \text {,asg. In this }}$ case, $f_{m}$ for $x_{\text {par }}$,asg and $x$ off $_{m \text {,asg }}$ are obtained from Steps (h) and (j), respectively. The concept of selection is elucidated in terms of the formulation given in (9). Otherwise, when the total number of chosen individuals is not adequate for 
population size, pop, then the offspring, $x_{\text {off }}$,asg, is selected as the next generation of $x$ par $_{m \text {,asg }}$ as illustrated in

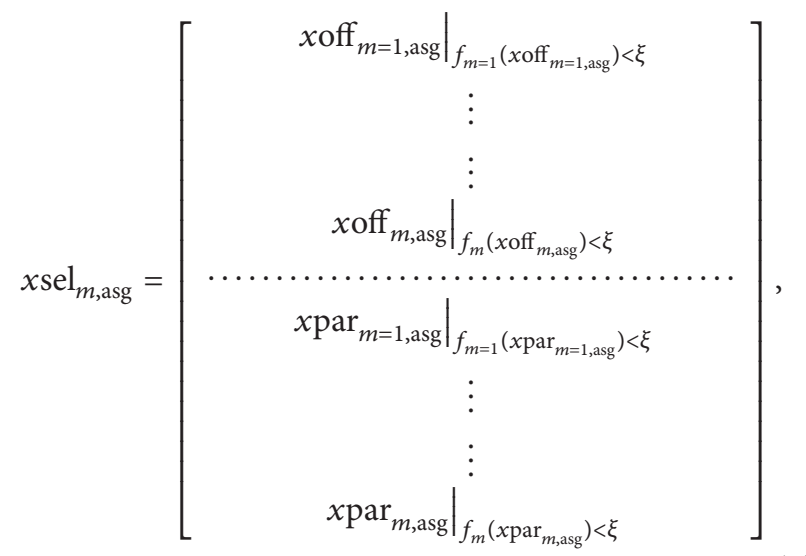

$$
x \operatorname{par}_{m, \text { asg }}= \begin{cases}x \operatorname{sel}_{m, \text { asg }}, & \text { if size }\left(x \operatorname{sel}_{m, \text { asg }}\right) \geq \text { pop } \\ x \text { off }_{m, \text { asg }}, & \text { if size }\left(x \operatorname{sel}_{m, \text { asg }}\right)<\text { pop }\end{cases}
$$

where $x$ sel $_{m \text {,asg }}$ is the best individuals selected from $x$ off ${ }_{m \text {,asg }}$ and $x$ par $_{m \text {,asg }}$ having $f_{m}<\xi ; f_{m}\left(x\right.$ off $\left._{m, \text { asg }}\right)$ is the $f_{m}$ corresponding to the $m$ th value of individual $x$ off $_{m \text {,asg }}$; $f_{m}\left(x \operatorname{par}_{m \text {,asg }}\right)$ is the $f_{m}$ corresponding to the $m$ th value of individual $x$ par $_{m \text {,asg }}$; and size $\left(x \mathrm{sel}_{m \text {,asg }}\right)$ is the size of $x \mathrm{sel}_{m \text {,asg }}$.

Step $(m)$. The convergence criteria for the EP optimization process is achieved when the mismatch between maximum fitness, $f_{\max }$, and minimum fitness, $f_{\min }$, is within a specified range, $\varepsilon$. $f_{\max }$ and $f_{\min }$ are the maximum and minimum values of $f_{m}$, respectively, obtained based on the $x \mathrm{par}_{m \text {,asg }}$ in Step (1):

$$
f_{\max }-f_{\min } \leq \varepsilon
$$

where $f_{\min }$ is the minimum value of $f_{m}$ or $\operatorname{LOLE}_{m \text {,asd=1 }}$ and $\varepsilon$ is the desired accuracy, 0.1 for an example [16].

Go to Step (f) for the next generation of EP optimization process when the mismatch does not reach to the desired level and the new value of $x$ par $_{m \text {,asg }}$ obtained in Step (l) will be used to calculate a new $\mathrm{PGt}_{m \text {, asg }}$ in Step (f). Otherwise, proceed to Step $(n)$ once the mismatch has reached the predetermined limit $\varepsilon$.

Step (n). Record the optimized multiobjective function of $\mathrm{CBM}_{\text {asg }}$ for the transfer case from assisting areas to an assisted area. The optimized multiobjective $\mathrm{CBM}_{\text {asg }}$ will be recorded at the last iteration of the optimization process. The $\mathrm{CBM}_{\mathrm{asg}}$ is obtained as the average value of $x \mathrm{par}_{m \text {,asg }}$ or $\mathrm{CBM}_{m \text {,asg }}$ associated with the assisting area previously calculated in Step (1). This implies that the $\mathrm{CBM}_{\text {asg }}$ is calculated through (12). Hence, the multiobjective function (M.O.F) comprising several optimized $\mathrm{CBM}_{\text {asg }}$ for the case of power transferred from the assisting areas can be expressed by (13). Then,
$\mathrm{LOLE}_{\mathrm{asg}}$ is computed based on the CBM allocated for each assisting area, $\mathrm{CBM}_{m \text {,asg }}$, as discussed in [19]. Consider

$$
\begin{aligned}
\mathrm{CBM}_{\mathrm{asg}} & =\mu\left(x \operatorname{par}_{m, \mathrm{asg}}\right)=\mu\left(\mathrm{CBM}_{m, \mathrm{asg}}\right), \\
\text { M.O.F } & =\left[\mathrm{CBM}_{\mathrm{asg}=1}, \mathrm{CBM}_{\mathrm{asg}=2}, \ldots, \mathrm{CBM}_{\mathrm{asg}=N \mathrm{asg}}\right] .
\end{aligned}
$$

Therefore, $\mathrm{CBM}_{\text {asd }}$ for an assisted area is calculated by summing the optimum amount of $\mathrm{CBM}_{\text {asg }}$ transferred from all the assisting areas as given in

$$
\mathrm{CBM}_{\mathrm{asd}=1}=\sum_{\mathrm{asg}=1}^{\text {Nasg }} \mathrm{CBM}_{\mathrm{asg}} \text {. }
$$

Step (o). Repeat Steps (a)-(n) several times in order to obtain numerous optimal solutions of multiobjective $\mathrm{CBM}_{\text {asg. }}$. These results will be applied into the Pareto optimal concept in such a way to find several superior multiobjective $\mathrm{CBM}_{\text {asg }}$. Figure 1 presents the flowchart of the proposed EP optimization technique used to determine several multiobjective functions of CBMs.

\section{Ranking Index in the Pareto Optimality Concept for the Best Selection of Optimal Multiobjective Capacity Benefit Margins}

Pareto optimality is a concept that has been commonly used to select several optimal solutions of the multiobjective $\mathrm{CBM}_{\text {asg }}$ designated as multiobjective $\mathrm{CBM}_{\text {asg }}^{\text {Pareto }}$. This implies that the concept of Pareto does not provide a single solution that can be considered as the global optima for a problem related to the multiobjective $\mathrm{CBM}_{\mathrm{asg}}$. This is important to the ISO since it will provide flexibility to select the optimal as well as the most inexpensive result of multiobjective $\mathrm{CBM}_{\text {asg }}^{\text {Pareto }}$. These inexpensive results usually fall under the cluster of the Pareto optimal front. However, it is not worthy to select an expensive optimal result of multiobjective $\mathrm{CBM}_{\text {asg }}$ and this type of solution is usually categorized under the cluster of non-Pareto optimal. Figure 2 shows an example elucidating two clusters of the Pareto optimal concept. In Figure 2, F1 represents the axis plane of $\mathrm{CBM}_{\mathrm{asg}=1}$ solution for the transfer case from assisting area 3 to assisted area 1. F2 is the axis plane of $\mathrm{CBM}_{\mathrm{asg}=2}$ solution for the transfer case from assisting area 2 to assisted area 1.

The EP optimization technique is performed several times in order to provide numerous optimal solutions of $\mathrm{CBM}_{\text {asg }}$. In addition, solution $x$ is the intersection point for the two $\mathrm{CBM}_{\text {asg }}$ results. The solutions $x$ marked with a circle represent the cluster of Pareto optimal front. Usually, the best optimal solution of $\mathrm{CBM}_{\text {asg }}$, so-called $\mathrm{CBM}_{\mathrm{asg}}^{\text {Pareto }}$, is selected from the cluster of Pareto optimal front. Solutions $x$ marked with $\times$ represent the cluster of non-Pareto optimal front which do not have the best optimal solution of $\mathrm{CBM}_{\text {asg }}$ due to their expensive multiobjective function. For instance, this can be observed through the comparison between $x_{1}$ and $x_{3}$, which have the same $C B M_{\text {asg=1 }}$ value for the $F 1$ axis, that is, the transfer case from assisting area 3 to assisted area 1. 


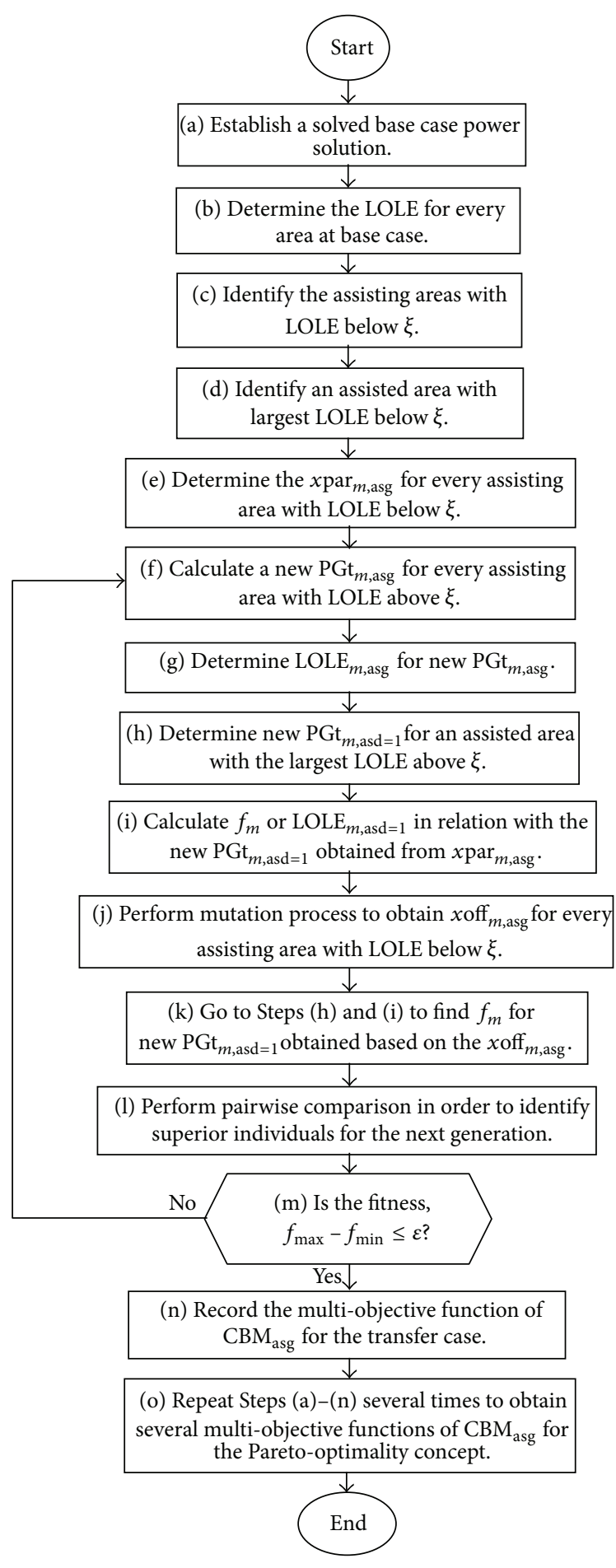

FIgURE 1: Proposed EP technique to determine several multiobjective functions of CBMs.

However, by referring to the $F 2$ axis, that is, the transfer case from assisting area 2 to assisted area $1, x_{3}$ yields to an expensive $\mathrm{CBM}_{\mathrm{asg}=2}$ value compared to $x_{1}$. Thus, $x_{3}$ and $x_{1}$ are optimal solutions of multiobjective $\mathrm{CBM}_{\text {asg }}$ which can be categorized under the non-Pareto and Pareto optimal fronts, respectively.

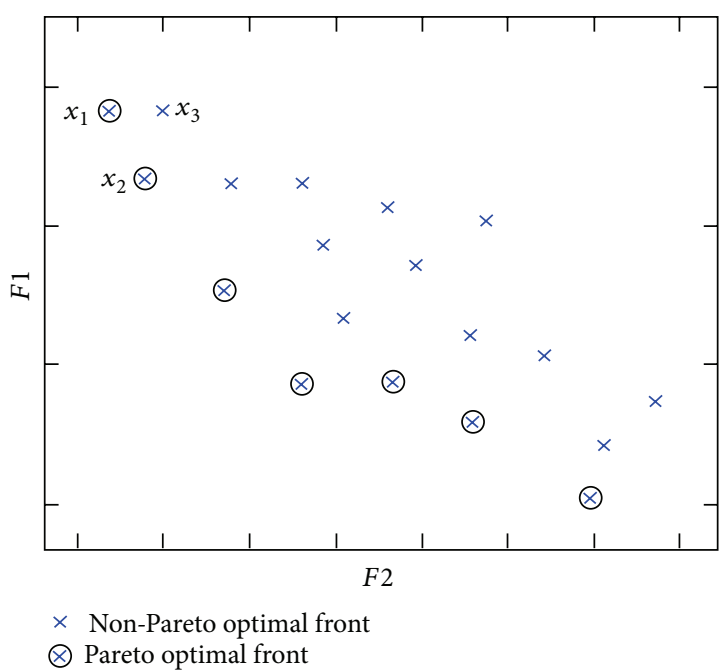

Figure 2: Pareto and non-Pareto optimal fronts for the multiobjective function $\mathrm{CBM}_{\text {asg }}$.

Theoretically, the Pareto optimal front can be defined as the solution $x$ that is not dominated by any other feasible solutions $x$ [20]. If the domination operator is labeled " $>$," the Pareto optimal concept can be described through the following criteria and this is referring to Figure 2.

(a) $x_{1}>x_{3}$ and $x_{2}>x_{3}$. Hence, the $x_{3}$ solution is said to be dominated or a non-Pareto optimal front solution.

(b) $x_{1}>x_{2}$ and $x_{2}>x_{1}$. Hence, the $x_{1}$ and $x_{2}$ solutions are said to be nondominated or Pareto optimal front solution.

The aforementioned criteria can also be used to determine the Pareto optimal front for a multiobjective function which has more than two transfer case solutions of $\mathrm{CBM}_{\text {asg }}$.

Furthermore, the selection of $\mathrm{CBM}_{\text {asg }}^{\text {Pareto }}$ will be performed by the ISO according to the ranking index of either total LOLE or total LOLE difference. The proposed method has the advantage of introducing $\mathrm{CBM}_{\text {asg }}^{\text {Pareto }}$ which will also provide the optimum results of LOLE and LOLE difference located at the Pareto optimal front cluster. In the initial selection based on the ranking index of total LOLE, $\mathrm{CBM}_{\text {asg }}^{\text {Pareto }}$ is arranged according to the ranking index of total LOLE sorted in an ascending order. Then, the $\mathrm{CBM}_{\mathrm{asg}}^{\text {Pareto }}$ is selected in accordance with the ranking index of total LOLE as shown in

$$
\mathrm{CBM}_{\text {asg }}^{\text {Pareto }} \in \operatorname{Rank}(\text { total LOLE) }
$$

where

$$
\text { total LOLE }=\sum_{\text {asg }=1}^{\text {Nasg }} \text { LOLE }_{\text {asg }} .
$$

Equation (15) shows that $\mathrm{CBM}_{\text {asg }}^{\text {Pareto }}$ is selected based on the ranking index of reliability or total LOLE in the assisting areas. 
In the subsequent selection based on the ranking index of total LOLE difference, $\mathrm{CBM}_{\mathrm{asg}}^{\text {Pareto }}$ is arranged according to the ranking index of total LOLE difference sorted in an ascending order. Then, the ranking index of total LOLE difference is used to select $\mathrm{CBM}_{\text {asg }}^{\text {Pareto }}$. This is illustrated in

$$
\mathrm{CBM}_{\text {asg }}^{\text {Pareto }} \in \operatorname{Rank}(\text { total } \Delta \mathrm{LOLE})
$$

where

$$
\text { total } \Delta \mathrm{LOLE}=\sum_{\mathrm{asg}=1}^{\text {Nasg }}\left(\mathrm{LOLE}_{\mathrm{asg}}-\mathrm{LOLE}_{\mathrm{asg}}^{o}\right),
$$

where LOLE $E_{\text {asg }}^{o}$ is the LOLE at the base case condition of each assisting area.

Finally, the selected $\mathrm{CBM}_{\text {asg }}^{\text {Pareto }}$ will be taken into account as firm and nonfirm transfer margins in the ATC determination.

\section{Firm and Nonfirm Available Transfer Capability Determination}

This section discusses the ATC determination that takes into account each optimum $\mathrm{CBM}_{\text {asg }}^{\text {Pareto }}$ value selected by referring to the ranking index of total LOLE and total LOLE difference. The proposed method uses the iterative power flow solutions to determine ATC by taking into account $\mathrm{CBM}_{\text {asg }}^{\text {Pareto }}$ for the transfer case from an assisting area to an assisted area [21]. Basically, the determination of ATC considering $\mathrm{CBM}_{\text {asg }}^{\text {Pareto }}$ requires an iterative power flow solution to be performed at every increase of generation capacity and load at the respective selling and buying areas until one of the system constraints is met. This method is used to determine ATC considering $\mathrm{CBM}_{\mathrm{asg}}^{\text {Pareto }}$ for the next case of power transfer. It is important to note that two approaches are available to calculate ATC taking into account $\mathrm{CBM}_{\text {asg }}^{\text {Pareto }}$ as firm or nonfirm transfer. In the former approach, the assisting and assisted areas are experiencing changes in total generation capacity according to the firm transfer of $\mathrm{CBM}_{\text {asg }}^{\text {Pareto }}$, whereas, in the latter approach, ATC is determined as the total transfer capability, TTC, reduced by $\mathrm{CBM}_{\text {asg }}^{\text {Pareto }}$. The procedure for both approaches discussed in this paper are implemented as follows.

Step (a). Establish a solved base power flow solution.

Step (b). Specify the selling and buying areas for a power transfer.

Step (c). Proceed to Step (e) if $\mathrm{CBM}_{\text {asg }}^{\text {Pareto }}$ is considered to be a nonfirm transfer. Otherwise, adjust the generation outputs according to $\mathrm{CBM}_{\text {asg }}^{\text {Pareto }}$ for all areas. The modification of generation outputs in assisted area and assisting area is done by using (19) and (20), respectively,

$$
\begin{gathered}
\text { new } \mathrm{PG}_{g}^{\text {asd }=1}=\mathrm{PG}_{g}^{\text {asd }=1}-\frac{\mathrm{PG}_{g}^{\text {asd }=1}}{\sum_{g=1}^{\mathrm{NG}} \mathrm{PG}_{g}^{\text {asd }=1}} \sum_{\text {asg }=1}^{\text {Nasg }} \mathrm{CBM}_{\text {asg }}^{\text {Pareto }} \\
\text { new } \mathrm{PG}_{g}^{\text {asg }}=\mathrm{PG}_{g}^{\text {asg }}+\frac{\mathrm{PG}_{g}^{\text {asg }}}{\sum_{g=1}^{\mathrm{NG}} \mathrm{PG}_{g}^{\text {asg }}} \mathrm{CBM}_{\text {asg }}^{\text {Pareto }}
\end{gathered}
$$

Notice that (19) and (20) may cause the assisting area to transfer its reverse generation capacity $\left(\mathrm{CBM}_{\mathrm{asg}}^{\text {Pareto }}\right)$ for compensating the generation deficiency which may occur in the assisted area. This is different from what has been dealt previously with, with (4) and (6) whereby the generating capacity of an assisting area and assisted area is decreased and increased, respectively, in order to identify the amount of generation capacity reserved for the CBM so that LOLE will be less than $\xi$.

Step (d). Perform the power flow solution to allow an assisting area to transfer power based $\mathrm{CBM}_{\text {asg }}^{\text {Pareto }}$ required for compensating the generation deficiency occurring in the assisted area.

Step (e). Simultaneously, increase the power injection and extraction at the selling and buying areas, respectively, until either one of the line flows or voltage constraints is met through the load flow solution. The lower and upper voltage limits are considered to be 0.90 and 1.10 p.u., respectively. The injected power is referring to the increase of generation capacity in a selling area resulting in a power transfer which will be extracted by the load increased in a buying area. The maximum power transfer so-called TTC is acquired once the increased power flow solution has met one of the system constraints as mentioned previously.

Step $(f)$. Calculate the ATC at three different cases of TTC determined in Step (e). In conjunction with the $\mathrm{TTC}^{o}$ for the first case, the ATC at base case condition is obtained by employing (21) which does not require the execution of Steps (c) and (d):

$$
\mathrm{ATC}^{o}=\mathrm{TTC}^{o}-\mathrm{ETC}
$$

where $\mathrm{TTC}^{o}$ is the total transfer capability or the maximum power transfer at base case condition obtained and ETC is the existing transmission commitment or base case load flow solution considering system components variations.

With regard to the $\mathrm{TTC}^{o}$ and $\mathrm{CBM}_{\mathrm{asg}}^{\text {Pareto }}$ for the second case, (22) is used to calculate ATC taking into account nonfirm transfer of CBM:

$$
\mathrm{ATC}_{\text {nonfirm }}=\mathrm{TTC}^{o}-\mathrm{CBM}_{\mathrm{asg}}^{\text {Pareto }}-\mathrm{ETC} \text {. }
$$

By referring to $\left.\mathrm{TTC}\right|_{\mathrm{CBM}_{\text {asg }}^{\text {Pareto }}}$ given for the third case, the $\mathrm{CBM}$ is taken as a firm transfer for ATC determination and the associated formulation is introduced through

$$
\mathrm{ATC}_{\text {firm }}=\mathrm{TTC}_{\mathrm{CBM}_{\text {asg }}^{\text {Pareto }}}-\mathrm{ETC} .
$$


By referring to (23), the modification of generation capacity is performed in Step (c) consecutively with the load flow solution performed in Step (d) so that the ATC is determined by considering the firm transfer of CBM.

Step $(g)$. Repeat Steps (a)-(f) to determine ATC for the next transfer case between the selling and buying areas. The determination of ATC for the next transfer case will also consider the same CBMs determined for the assisting and assisted areas.

The flowchart of ATC determination that takes into account the firm and nonfirm transfer margins of $\mathrm{CBM}_{\text {asg }}^{\text {Pareto }}$ is illustrated in Figure 3.

\section{Results and Discussion}

A modified IEEE-RTS79 is used to demonstrate the effectiveness of the proposed method in determining the CBM for each area $[19,22]$. The generating units and transmission line information are given in $[19,22]$. In this paper, the specified value of LOLE limit, $\xi$, is assumed to be $2.4 \mathrm{hrs} / \mathrm{yr}$.

5.1. Capacity Benefit Margin Considering Interconnected System Reliability. In the base case condition of a modified IEEE-RTS79, the total generation, total load, and LOLE associated with each area is presented in Table 1. Based on the predetermined LOLE, areas 2 and 3 are considered the assisting areas and area 1 is referred to as the assisted area.

Table 2 presents the results of CBM considering tie-line reliability and is determined using the basic methodology discussed in [19]. It is observed that $88 \mathrm{MW}$ and $33 \mathrm{MW}$ are the amount of CBM reserved for the transfer from assisting areas 2 and 3 to area 1, respectively, resulting in the LOLE value being below $2.4 \mathrm{hrs} / \mathrm{yr}$. Hence, new generation capacities of $2156 \mathrm{MW}, 1660 \mathrm{MW}$, and $751 \mathrm{MW}$ are obtained for areas 1,2 , and 3 , respectively.

5.2. Multiobjective Capacity Benefit Margins Result Determined by the Ranking Index in Pareto-Based Evolutionary Programming Technique. It is noteworthy that Table 1 has presented the total generation capacity and total load for every area at base case condition of IEEE-RTS79. In conjunction with this matter, the LOLE less than $2.4 \mathrm{hrs} / \mathrm{yr}$ implies that the assisting areas 2 and 3 have sufficient amount of total reserve generation capacity that can be used as a reference to estimate the amount of CBM for accommodating the generation deficiency which may occur in the assisted area 1 with LOLE above $2.4 \mathrm{hrs} / \mathrm{yr}$. Hence, the EP optimization technique is used to perform simultaneous determination of CBM that can be transferred from the assisting areas 2 and 3 towards the assisted area 1.

In the EP optimization technique, there are 10 individuals in a population representing the $x \operatorname{par}_{m, \mathrm{asg}=1}$ or CBMs for assisting area 2 . The same situation goes to the next population representing the $x \operatorname{par}_{m, \mathrm{asg}=2}$ or CBMs for assisting area 3. The initial process of EP optimization technique will randomly generate a uniform distribution of $x \mathrm{par}_{m \text {,asg }}$ using (1) based on the reserve generating capacity available

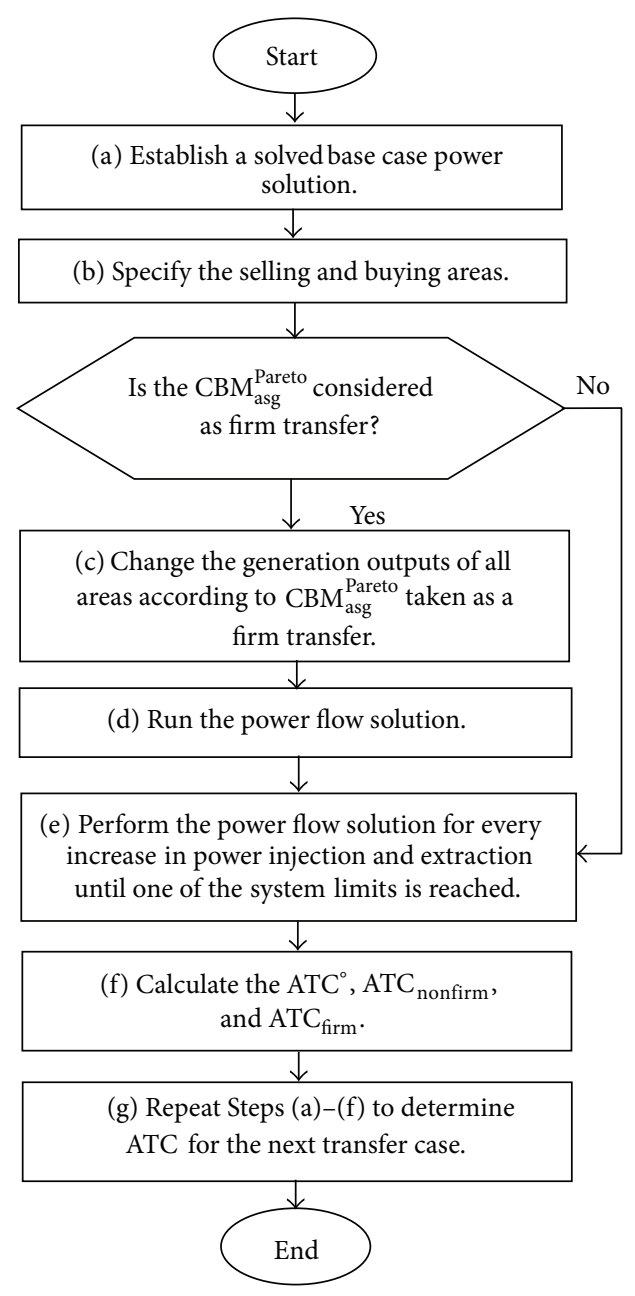

FIGURE 3: Flowchart of firm and nonfirm ATC determination technique.

TABLE 1: Generation, load, and LOLE for the three areas.

\begin{tabular}{lccc}
\hline Area & Generation $[\mathrm{MW}]$ & Load [MW] & LOLE [hrs/yr] \\
\hline 1 & 2035 & 1125 & 4.7756 \\
2 & 1748 & 1141 & 0.6380 \\
3 & 784 & 584 & 0.6917 \\
\hline
\end{tabular}

TABLE 2: CBM results considering interconnected system reliability using the method introduced in [19].

\begin{tabular}{lccc}
\hline Area & Generation [MW] & CBM [MW] & LOLE [hrs/yr] \\
\hline Assisted area 1 & 2156 & 121 & 2.3972 \\
Assisting area 2 & 1660 & 88 & 1.3943 \\
Assisting area 3 & 751 & 33 & 1.3569 \\
\hline
\end{tabular}

in the assisting area. In particular, the initial population, $x \operatorname{par}_{m \text {,asg=1 }}$, for assisting area 2 is obtained through the randomly generated variables that are in the range of $1 \mathrm{MW}$ and $607 \mathrm{MW}$. This signifies that $1748 \mathrm{MW}-1141 \mathrm{MW}=$ $607 \mathrm{MW}$ is the reserved generating capacity available in the assisting area 2 . In the overleaf case, that is, referring to 
the assisting area 3 , the initial population, $x \mathrm{par}_{m, \text { asg }=2}$, is obtained via the randomly generated variables which are within the range of $1 \mathrm{MW}$ and $200 \mathrm{MW}$. Both of the $x \mathrm{par}_{m \text {,asg }}$ representing the initial population for assisting area 2 and area 3 are tabulated in Table 3. Simultaneously, both of the initial populations are applied into the mutation in (7) and pairwise comparison process (10) to obtain $x \mathrm{off}_{m \text {,asg }}$ and a new $x$ par $_{m \text {,asg }}$, respectively, for the assisting areas 2 and 3 . All of the optimization process embedded in the EP optimization technique is repeated until the difference between maximum fitness, $f_{\max }$, and minimum fitness, $f_{\min }$, for the assisted area 1 is equal or less than the specified $\varepsilon=0.1$. In the last iteration of EP optimization process, the average value of $x \mathrm{par}_{m \text {,asg }}$ for both populations represents the optimum value of CBM for assisting areas 2 and 3 . The $x \mathrm{par}_{m \text {,asg }}$ obtained at the final iteration of EP optimization process are shown in Table 4 . In relation to each population of $x$ par $_{m \text {,asg }}$, it is obvious that a relatively similar value is obtained for all of the individuals, and the average value of $x \mathrm{par}_{m \text {,asg }}$ in (12) may yield to CBM specified for the assisting areas 2 and 3. This result is obtained only for one optimization run of EP technique. The EP optimization technique is executed for several times so that the Pareto optimal fronts of CBMs $\left(\mathrm{CBM}_{\mathrm{asg}}^{\text {Parto }}\right)$ are obtained which provides flexibility to the transmission provider in selecting optimum CBMs in tandem with the changes of economic, load-serving entity requirement or resource planner. The analysis of $\mathrm{CBM}_{\mathrm{asg}}^{\text {Pareto }}$ will be elucidated in the following discussion.

Figure 4 shows different optimized values of CBM obtained at every execution of the EP optimization process. The $x$-axis represents the CBM transferred from the assisting area 2 to assisted area 1 , whereas the $y$-axis represents the CBM transferred from assisting area 3 to assisted area 1.

It is observed that, with an increase in CBM associated with a particular assisting area, CBM at the other assisting area would decrease and vice versa. The best optimum values for the multiobjective function of CBMs are obtained based on the Pareto optimal front and the cluster for this case is illustrated in Figure 4. The other cluster represents the nonPareto optimal front of CBMs with excessive value which may yield to an invidious violation of power system security and ineffective utilization of the existing network resources. Figure 5 represents the cluster of Pareto optimal front of CBMs extracted from Figure 4. In the Pareto optimal front, the results of CBM have less potential in violating system security compared with the excessive amount of CBMs obtained based on the non-Pareto optimal front.

Furthermore, the Pareto optimal front approach used in the EP technique gives sufficient flexibility to the ISO in selecting the optimum value of CBM for every transfer case depending on the system requirements. This is obviously contradictory with CBM results tabulated in Table 2 which are obtained using a basic approach [19]. Based on the CBM results shown in Table 2, ISO does not have the flexibility to select other choices with suitable set of CBMs for compensating any generation deficiency at different system operating states. In relation to Figure 5, CBM results for each area yielding to the Pareto optimal front are also tabulated in

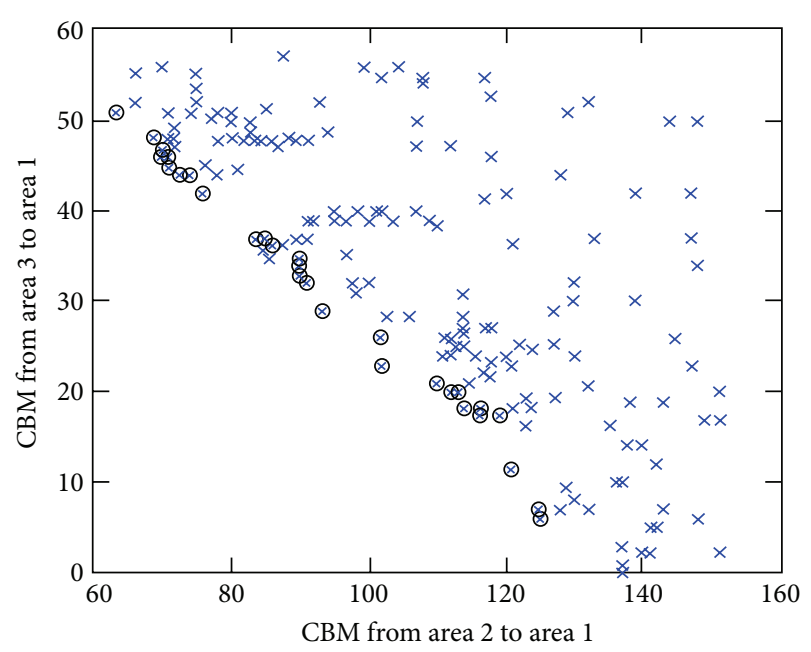

$\times$ Non-Pareto optimal front

$\otimes$ Pareto optimal front

Figure 4: Pareto and non-Pareto optimal fronts of CBM for the two transfer cases.

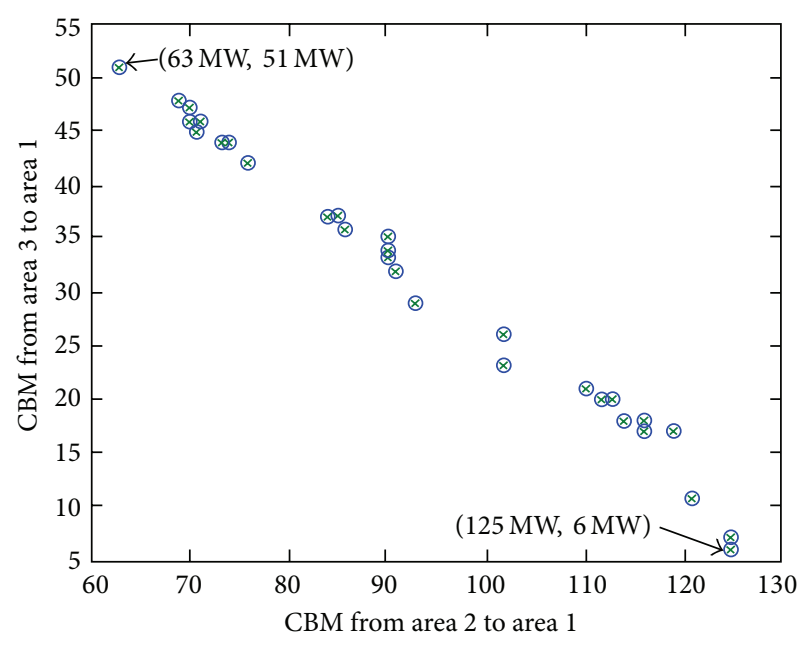

FIgURE 5: Pareto optimal fronts of CBMs for the two transfer cases.

Table 5. Every result of Pareto optimal front CBM will be used as a reference to estimate the power transferred from assisting areas 2 and 3 to accommodate possible generation deficiency in the assisted area 1.

It is observed that the Pareto optimal front of CBM values was obtained while fulfilling the LOLE criterion of less than $2.4 \mathrm{hrs} / \mathrm{yr}$. The other advantage of the proposed method is that $\mathrm{CBM}_{\text {asg }}^{\text {Pareto }}$ results also yield Pareto optimal front clusters of LOLE and difference in LOLE values. This can be verified in Figure 6 where LOLE located at the Pareto optimal front cluster refers to the $\mathrm{CBM}_{\text {asg }}^{\text {Pareto }}$ results obtained for each case of power transfer depicted in Figure 4. Consequently, the results of total LOLE obtained through (15) are arranged in ascending order and the ranking index is assigned to every result to distinguish the reliability of the assisting areas shown 
TABLE 3: Initial population of EP technique for the assisting areas 2 and 3.

\begin{tabular}{|c|c|c|c|c|}
\hline \multirow{2}{*}{ Number of individuals } & \multicolumn{2}{|c|}{ Assisting area 2} & \multicolumn{2}{|c|}{ Assisting area 3} \\
\hline & $x \mathrm{par}_{m, \mathrm{asg}=1}$ or CBM (MW) & LOLE (hrs/yr) & $x \operatorname{par}_{m, \mathrm{asg}=2}$ or CBM (MW) & LOLE (hrs/yr) \\
\hline 1 & 474.61 & 52.67 & 47.96 & 1.89 \\
\hline 2 & 237.57 & 5.22 & 71.63 & 3.44 \\
\hline 3 & 147.71 & 2.29 & 165.24 & 37.63 \\
\hline 4 & 246.18 & 5.46 & 4.08 & 0.70 \\
\hline 5 & 59.55 & 1.03 & 9.60 & 0.80 \\
\hline 6 & 81.11 & 1.25 & 34.80 & 1.43 \\
\hline 7 & 572.83 & 137.47 & 130.82 & 15.57 \\
\hline 8 & 581.37 & 148.06 & 147.35 & 23.20 \\
\hline 9 & 350.15 & 15.24 & 130.55 & 15.57 \\
\hline 10 & 37.29 & 0.85 & 91.19 & 5.62 \\
\hline
\end{tabular}

TABLE 4: Final population for the assisting areas 2 and 3 based on one run of EP optimization process.

\begin{tabular}{|c|c|c|c|c|}
\hline \multirow{2}{*}{ Number of individuals } & \multicolumn{2}{|c|}{ Assisting area 2} & \multicolumn{2}{|c|}{ Assisting area 3} \\
\hline & $x \mathrm{par}_{m, \mathrm{asg}=1}$ or CBM (MW) & LOLE (hrs/yr) & $x \mathrm{par}_{m, \mathrm{asg}=2}$ or CBM (MW) & LOLE (hrs/yr) \\
\hline 1 & 86 & 1.32 & 35 & 1.43 \\
\hline 2 & 86 & 1.32 & 35 & 1.43 \\
\hline 3 & 86 & 1.32 & 35 & 1.43 \\
\hline 4 & 86 & 1.32 & 35 & 1.43 \\
\hline 5 & 86 & 1.32 & 35 & 1.43 \\
\hline 6 & 86 & 1.32 & 35 & 1.43 \\
\hline 7 & 86 & 1.32 & 35 & 1.43 \\
\hline 8 & 86 & 1.32 & 35 & 1.43 \\
\hline 9 & 85 & 1.29 & 35 & 1.43 \\
\hline 10 & 85 & 1.29 & 35 & 1.43 \\
\hline
\end{tabular}

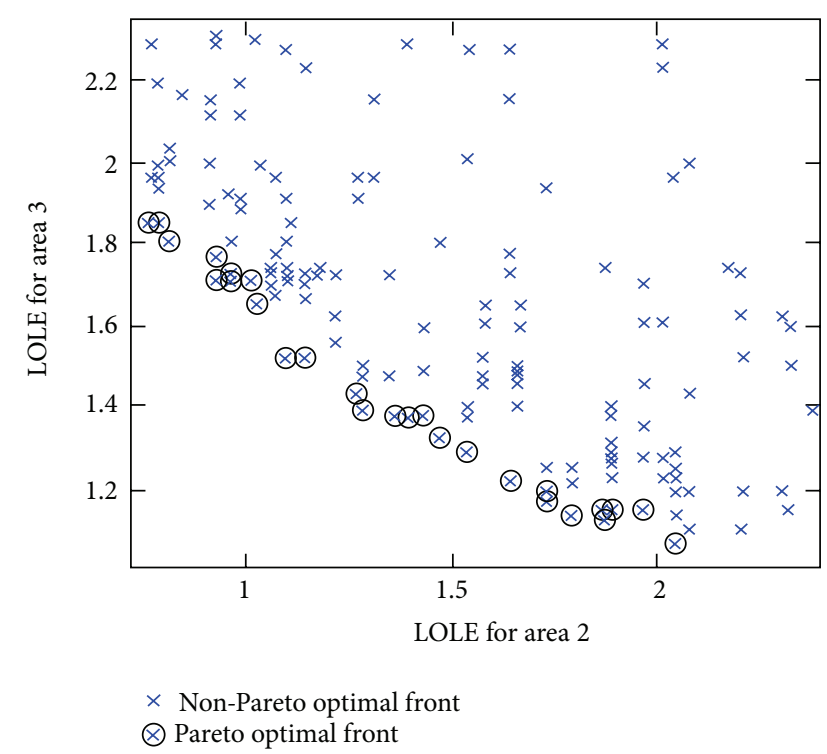

Figure 6: Pareto optimal fronts of LOLE for areas 2 and 3.

in Table 6. With respect to each value of total LOLE, total $\mathrm{CBM}_{\text {asg }}^{\text {Pareto }}$ was obtained based on the two transfer cases also shown in Table 6. The total $\mathrm{CBM}_{\text {asg }}^{\text {Pareto }}$ is equivalent to $\mathrm{CBM}$ for an assisted area, $\mathrm{CBM}_{\text {asd=1 }}$.

Figure 7 represents the difference between LOLE values located at the Pareto optimal front cluster. The results are referring to the $\mathrm{CBM}_{\text {asg }}^{\text {Pareto }}$ obtained based on the power transfer cases shown in Figure 4. Then, the results of total LOLE difference calculated using (17) were arranged in ascending order and the ranking index is assigned to each result indicating level of reliability available for the assisting areas as shown in Table 6 . Table 6 reveals that the total $\mathrm{CBM}_{\text {asg }}^{\text {Pareto }}$ or $\mathrm{CBM}_{\text {asd }}^{\text {Pareto }}$ values were arranged according to the total LOLE and total LOLE difference possessing the same ranking index. The results divulge that the Pareto-based EP method has the advantage of providing simultaneous optimum results of $\mathrm{CBM}_{\text {asg }}^{\text {Pareto }}$, LOLE, and difference of LOLE in which all are located at the Pareto optimal front cluster.

As noted earlier and clearly presented in Table 6, the proposed method has the advantage of providing several choices of CBM that can be selected by ISO based on the ranking index of total LOLE and/or total LOLE difference. For instance, the ISO shall set the $\mathrm{CBM}_{\text {asg }}^{\text {Pareto }}$, respectively, to $125 \mathrm{MW}$ and $6 \mathrm{MW}$ for the transfer case from assisting areas 2 and 3 , respectively, to the assisted area 1 so that the assisting areas will operate in a highly reliable condition because 
TABLE 5: Pareto optimal front of CBM values for each area.

\begin{tabular}{|c|c|c|c|c|c|c|}
\hline \multirow{2}{*}{ EP run } & \multicolumn{2}{|c|}{ Assisted area 1} & \multicolumn{2}{|c|}{ Assisting area 2} & \multicolumn{2}{|c|}{ Assisting area 3} \\
\hline & CBM [MW] & LOLE $[\mathrm{hrs} / \mathrm{yr}]$ & CBM [MW] & LOLE [hrs/yr] & CBM [MW] & LOLE [hrs/yr] \\
\hline 1 & 114 & 2.3997 & 63 & 1.0646 & 51 & 2.0485 \\
\hline 2 & 117 & 2.3627 & 69 & 1.1475 & 48 & 1.8874 \\
\hline 3 & 117 & 2.3794 & 73 & 1.1739 & 44 & 1.731 \\
\hline 4 & 121 & 2.3967 & 85 & 1.2913 & 36 & 1.4705 \\
\hline 5 & 117 & 2.3656 & 70 & 1.1458 & 47 & 1.9693 \\
\hline 6 & 117 & 2.3723 & 71 & 1.1237 & 46 & 1.8714 \\
\hline 7 & 116 & 2.3867 & 70 & 1.1458 & 46 & 1.8714 \\
\hline 8 & 116 & 2.3941 & 71 & 1.1237 & 45 & 1.7887 \\
\hline 9 & 118 & 2.3641 & 74 & 1.1847 & 44 & 1.731 \\
\hline 10 & 118 & 2.3667 & 76 & 1.2076 & 42 & 1.6394 \\
\hline 11 & 121 & 2.3996 & 86 & 1.3183 & 35 & 1.431 \\
\hline 12 & 122 & 2.3785 & 86 & 1.3183 & 36 & 1.4705 \\
\hline 13 & 125 & 2.3411 & 90 & 1.3775 & 35 & 1.431 \\
\hline 14 & 121 & 2.3954 & 84 & 1.2902 & 37 & 1.539 \\
\hline 15 & 122 & 2.3766 & 85 & 1.2913 & 37 & 1.539 \\
\hline 16 & 124 & 2.3534 & 90 & 1.3775 & 34 & 1.3913 \\
\hline 17 & 123 & 2.3695 & 90 & 1.3775 & 33 & 1.3569 \\
\hline 18 & 123 & 2.3711 & 91 & 1.3914 & 32 & 1.2769 \\
\hline 19 & 122 & 2.3931 & 93 & 1.428 & 29 & 1.2597 \\
\hline 20 & 128 & 2.3248 & 102 & 1.5166 & 26 & 1.1351 \\
\hline 21 & 125 & 2.3697 & 102 & 1.5166 & 23 & 1.0929 \\
\hline 22 & 131 & 2.3091 & 110 & 1.6479 & 21 & 1.0247 \\
\hline 23 & 132 & 2.3999 & 112 & 1.7002 & 20 & 1.0107 \\
\hline 24 & 133 & 2.3934 & 113 & 1.7095 & 20 & 1.0107 \\
\hline 25 & 132 & 2.3985 & 114 & 1.7198 & 18 & 0.9511 \\
\hline 26 & 134 & 2.373 & 116 & 1.7116 & 18 & 0.9511 \\
\hline 27 & 133 & 2.3841 & 116 & 1.7116 & 17 & 0.9235 \\
\hline 28 & 136 & 2.3455 & 119 & 1.7702 & 17 & 0.9235 \\
\hline 29 & 132 & 2.3932 & 121 & 1.8074 & 11 & 0.8044 \\
\hline
\end{tabular}

the aforementioned power transfers are obtained based on the lowest total LOLE of $2.608 \mathrm{hrs} / \mathrm{yr}$ at the 1 st ranking index. The combination of $\mathrm{CBM}_{\text {asg }}^{\text {Pareto }}$ for both transfer cases will provide a total $\mathrm{CBM}_{\text {asg }}^{\text {Pareto }}$ of $131 \mathrm{MW}$ which results in the lowest total LOLE difference of $1.278 \mathrm{hrs} / \mathrm{yr}$ at the 1st ranking index as shown in Table 6. Due to a relatively large total $\mathrm{CBM}_{\text {asg }}^{\text {Pareto }}$ of $131 \mathrm{MW}$, the tie-line capacity will not be fully utilized as a medium power transfer based ATC for electricity transfer. The total $\mathrm{CBM}_{\text {asg }}^{\text {Pareto }}$ of $131 \mathrm{MW}$ can also be obtained at the 10th ranking index as shown in Table 6. However, a total $\mathrm{CBM}_{\text {asg }}^{\text {Pareto }}$ of $131 \mathrm{MW}$ at the 10th ranking index will not be the best choice for the ISO since the assisting areas will operate in a less reliable condition due to the total LOLE of $2.673 \mathrm{hrs} / \mathrm{yr}$ and total LOLE difference of $1.343 \mathrm{hrs} / \mathrm{yr}$. Furthermore, the 10th ranking index yields to a result that is close with the largest total $\mathrm{CBM}_{\text {asg }}^{\text {Pareto }}$ of $136 \mathrm{MW}$ located at the 12 th ranking index. However, total LOLE of $2.694 \mathrm{hrs} / \mathrm{yr}$ and total LOLE difference of $1.364 \mathrm{hrs} / \mathrm{yr}$ signify a reasonable or moderately reliable operation of the assisting areas in conjunction with the largest total $\mathrm{CBM}_{\mathrm{asg}}^{\text {Pareto }}$ of $136 \mathrm{MW}$ at the 12 th ranking index.

In another situation whereby the ISO is not interested in a highly reliable condition of a power system, the $\mathrm{CBM}_{\text {asg }}^{\text {Pareto }}$ of $70 \mathrm{MW}$ can be selected for the transfer case from assisting area 2 to area 1 and the $\mathrm{CBM}_{\text {asg }}^{\text {Pareto }}$ of $47 \mathrm{MW}$ can be chosen for the transfer case from assisting area 3 to assisted area 1. This would be a less reliable choice prior to the largest value of total LOLE which is $3.115 \mathrm{hrs} / \mathrm{yr}$ at the 29th ranking index as tabulated in Table 6. Consequently, the total $\mathrm{CBM}_{\text {asg }}^{\text {Pareto }}$ of $117 \mathrm{MW}$ is obtained contributing to the largest total LOLE difference of $1.785 \mathrm{hrs} / \mathrm{yr}$ located at the 29th ranking index. For this case, a highly reliable condition incurred from 
TABLE 6: CBM results with ranking index of total LOLE and total LOLE difference.

\begin{tabular}{|c|c|c|c|c|c|}
\hline $\begin{array}{l}\mathrm{CBM}_{\text {asd }}^{\text {Paret }} \\
{[\mathrm{MW}]}\end{array}$ & $\begin{array}{c}\mathrm{BM}_{\text {asg }}^{\text {Pareto }} \text { from area } 2 \\
\text { to area } 1[\mathrm{MW}]\end{array}$ & $\begin{array}{c}\mathrm{CBM}_{\text {asg }}^{\text {Pareto }} \text { from area } 3 \\
\text { to area } 1[\mathrm{MW}]\end{array}$ & Total LOLE $[\mathrm{hrs} / \mathrm{yr}]$ & $\begin{array}{l}\text { Total difference of } \\
\text { LOLE }[\mathrm{hrs} / \mathrm{yr}]\end{array}$ & Rank index \\
\hline 131 & 125 & 6 & 2.608 & 1.278 & 1 \\
\hline 125 & 102 & 23 & 2.610 & 1.280 & 2 \\
\hline 132 & 121 & 11 & 2.612 & 1.282 & 3 \\
\hline 132 & 125 & 7 & 2.629 & 1.300 & 4 \\
\hline 133 & 116 & 17 & 2.635 & 1.305 & 5 \\
\hline 128 & 102 & 26 & 2.652 & 1.322 & 6 \\
\hline 134 & 116 & 18 & 2.663 & 1.333 & 7 \\
\hline 123 & 91 & 32 & 2.668 & 1.339 & 8 \\
\hline 132 & 114 & 18 & 2.671 & 1.341 & 9 \\
\hline 131 & 110 & 21 & 2.673 & 1.343 & 10 \\
\hline 122 & 93 & 29 & 2.688 & 1.358 & 11 \\
\hline 136 & 119 & 17 & 2.694 & 1.364 & 12 \\
\hline 132 & 112 & 20 & 2.711 & 1.381 & 13 \\
\hline 133 & 113 & 20 & 2.720 & 1.391 & 14 \\
\hline 123 & 90 & 33 & 2.734 & 1.405 & 15 \\
\hline 124 & 90 & 34 & 2.769 & 1.439 & 16 \\
\hline 122 & 86 & 36 & 2.789 & 1.459 & 17 \\
\hline 125 & 90 & 35 & 2.809 & 1.479 & 18 \\
\hline 121 & 84 & 37 & 2.829 & 1.500 & 19 \\
\hline 122 & 85 & 37 & 2.830 & 1.501 & 20 \\
\hline 118 & 76 & 42 & 2.847 & 1.517 & 21 \\
\hline 117 & 73 & 44 & 2.905 & 1.575 & 22 \\
\hline 116 & 71 & 45 & 2.912 & 1.583 & 23 \\
\hline 118 & 74 & 44 & 2.916 & 1.586 & 24 \\
\hline 117 & 71 & 46 & 2.995 & 1.665 & 25 \\
\hline 116 & 70 & 46 & 3.017 & 1.688 & 26 \\
\hline 117 & 69 & 48 & 3.035 & 1.705 & 27 \\
\hline 114 & 63 & 51 & 3.113 & 1.783 & 28 \\
\hline 117 & 70 & 47 & 3.115 & 1.785 & 29 \\
\hline
\end{tabular}

a specific amount of CBM reserved through tie-line capacity is not the main intention for the ISO. Besides, ISO is more interested in the utilization of tie-line capacity for ATC in order to enhance and perform as an important role in the electricity market. Similar to the 29th ranking index, the $\mathrm{CBM}_{\text {asg }}^{\text {Parto }}$ of $117 \mathrm{MW}$ at the 22nd ranking index can also be used in this case study. It has the advantage in providing total LOLE of $2.905 \mathrm{hrs} / \mathrm{yr}$ and total LOLE difference of $1.575 \mathrm{hrs} / \mathrm{yr}$ which is much better than the results obtained at the 29th ranking index. By comparing with the total CBM of $117 \mathrm{MW}$ at the 22nd ranking index, ISO may choose the lowest value of total CBM, that is, $114 \mathrm{MW}$ at the 28th ranking index, only when the objective is not solely on the reliability improvement of the assisting areas.

In a detailed analysis, ISO may select the $\mathrm{CBM}_{\text {asg }}^{\text {Pareto }}$ of $90 \mathrm{MW}$ and $33 \mathrm{MW}$ for the transfer case from the assisting areas 2 and 3 to the assisted area 1, respectively, so that the assisting areas are operating at the mid ranking level (index 15) having the total LOLE of $2.734 \mathrm{hrs} / \mathrm{yr}$ and total LOLE difference of $1.405 \mathrm{hrs} / \mathrm{yr}$. This indicates that ISO has chosen the value of $\mathrm{CBM}_{\text {asg }}^{\text {Parto }}$ for both transfer cases resulting in $50 \%$ priority on the reliability of assisting areas and $50 \%$ priority on the power transfer based ATC reserved for electricity market activities. The aforementioned discussion shows that the optimal value of CBM specified for each case of power transfer is actually dependent on similar ranking indices of total LOLE and total LOLE difference.

The previous results have well demonstrated that $\mathrm{CBM}_{\mathrm{asg}}^{\text {Parto }}$, LOLEs, and difference of LOLEs clustered in the Pareto optimal front are the criteria to be satisfied by the ISO before conducting the finest selection of $\mathrm{CBM}_{\text {asg }}^{\text {Parto }}$. The performance of the Pareto optimal front embedded in the proposed optimization technique is not limited only to the $\mathrm{CBM}_{\text {asg }}^{\text {Pareto }}$ value that provides the highest reliability 


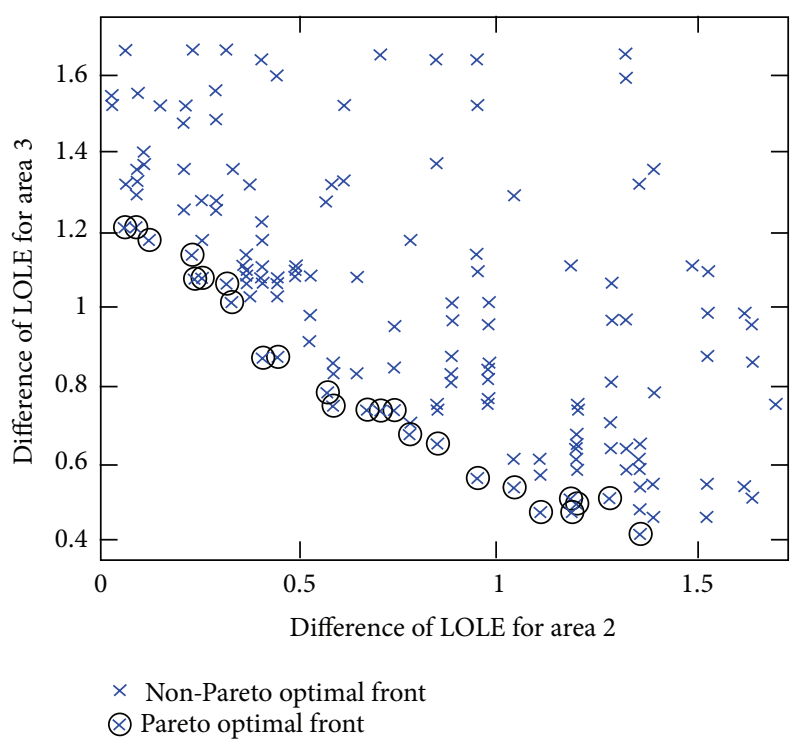

FIGURE 7: Pareto optimal fronts of LOLE difference for areas 2 and 3.

of assisting areas due to the lowest total LOLE and total LOLE difference associated with the 1st ranking index. Nevertheless, it also is not confined to the $\mathrm{CBM}_{\text {asg }}^{\text {Pareto }}$ value with large amount of ATC yielding to the largest total LOLE and total LOLE difference selected at the 29th ranking index. This implies that ISO has several choices for CBM for each case of power transfer depending on the ranking index selected based on the Pareto optimal front of total LOLE and total LOLE difference.

5.3. Performance Comparison with Existing Capacity Benefit Margin Calculation Methods. It is worthwhile to mention that the proposed method is robust in providing simultaneous optimum results of the $\mathrm{CBM}_{\text {asg }}^{\text {Pareto }}$, LOLE, and difference in LOLE, all of which are located at the Pareto optimal front cluster. In the proposed method, the ranking index has the advantage of providing a clearer depiction on the relationship between the three optimal results which will be a great help to the ISO in making the finest decision for selecting optimum CBM values. This is contradictory to other methods in [17], whereby the optimization process is performed separately to find the minimum total LOLE, minimum total LOLE difference, or minimum CBM considering weight of the tie-lines. As shown in Figure 8, the lowest total LOLE of $2.608 \mathrm{hrs} / \mathrm{yr}$ and lowest total LOLE difference of $1.278 \mathrm{hrs} / \mathrm{yr}$, computed using the method presented in [17], will give a total CBM result of $131 \mathrm{MW}$ which is quite large according to the Pareto optimal front tabulated in Table 6. Using both methods discussed in [17], ISO does not have a choice other than to utilize a large total CBM value of $131 \mathrm{MW}$ to ensure a highly reliable operating condition of the assisting areas in accordance with the lowest total LOLE of $2.608 \mathrm{hrs} / \mathrm{yr}$ and lowest total LOLE difference of $1.278 \mathrm{hrs} / \mathrm{yr}$. Thus, the proposed method of Pareto optimal front provides a solution to the abovementioned problem by

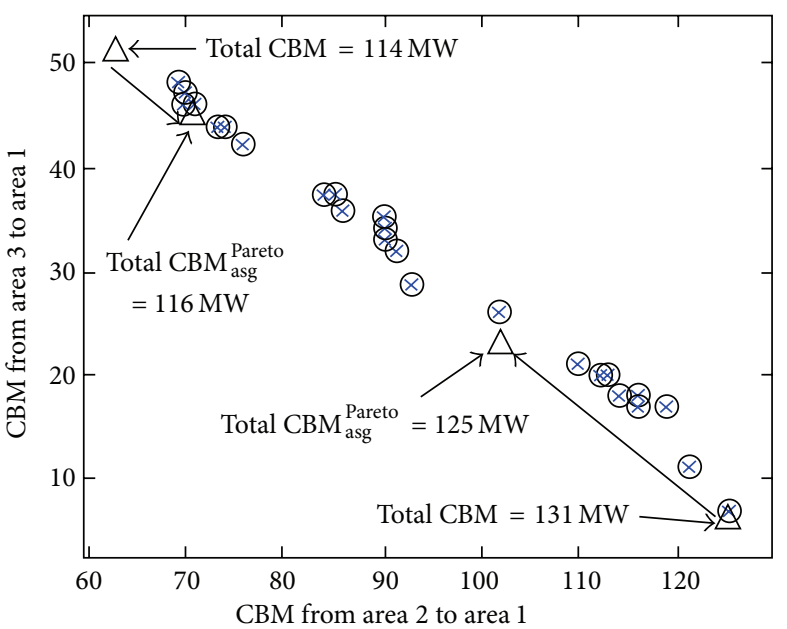

Figure 8: Total $\mathrm{CBM}_{\text {asg }}^{\text {Pareto }}$ selection based on the ranking index in Pareto optimal front concept.

providing the total $\mathrm{CBM}_{\mathrm{asg}}^{\text {Pareto }}$ of $125 \mathrm{MW}$ at the 2 nd ranking index considered as the other option that is smaller than the total CBM of $131 \mathrm{MW}$ at the 1st ranking index in Table 6 and Figure 8. The result of total $\mathrm{CBM}_{\text {asg }}^{\text {Pareto }}$, that is, $125 \mathrm{MW}$ at the 2 nd ranking index, also provides a highly reliable operating condition for the assisting areas that are nearly identical with the lowest total LOLE and lowest total LOLE difference at the 1st ranking index. Consequently, the total $\mathrm{CBM}_{\text {asg }}^{\text {Parto }}$ of $125 \mathrm{MW}$ at the 2 nd ranking index provides a more conservative space to transfer the power based ATC compared with the total CBM of $131 \mathrm{MW}$ at the 1st ranking index.

The method discussed in [17] provides some limited choices of CBM results as it considers the weight specified on each tie-line. However, the proposed method provides several $\mathrm{CBM}_{\text {asg }}^{\text {Pareto }}$ values without considering the weight for the tie-lines. Once the tie-line weight is not considered in [17], the minimum total $\mathrm{CBM}$ of $114 \mathrm{MW}$ is obtained. It is depicted in Figure 8 and Table 6 that the total CBM of $114 \mathrm{MW}$ is obtained at the assisted area when the CBMs of $63 \mathrm{MW}$ and $51 \mathrm{MW}$ are transferred from the assisting areas 2 and 3, respectively. However, the total LOLE of $3.113 \mathrm{hrs} / \mathrm{yr}$ and total LOLE difference of $1.783 \mathrm{hrs} / \mathrm{yr}$ are relatively large at the 28th ranking index although the minimum total CBM of $114 \mathrm{MW}$ is obtained using the abovementioned equation given in [17]. Therefore, the proposed Pareto optimal front concept is used to provide several choices of solution that are relatively similar to the minimum total CBM of $114 \mathrm{MW}$. For this case, the total $\mathrm{CBM}_{\mathrm{asg}}^{\text {Parto }}$ of $116 \mathrm{MW}$ is chosen from the 23rd ranking index of Pareto optimal front and it is the nearest value to the minimum total CBM of 114 MW. By referring to Figure 8 and Table 6 , it can be observed that the total $\mathrm{CBM}_{\text {asg }}^{\text {Pareto }}$ of $116 \mathrm{MW}$ will improve the reliability of the assisting areas due to the total LOLE of $2.912 \mathrm{hrs} / \mathrm{yr}$ and total LOLE difference of $1.583 \mathrm{hrs} / \mathrm{yr}$ which are smaller than the LOLE results obtained from the minimum total CBM of $114 \mathrm{MW}$. For other cases of 
TABLE 7: Results of ATC from area 1 to area 2.

\begin{tabular}{|c|c|c|c|}
\hline EP run & $\mathrm{ATC}_{\text {base }}[\mathrm{MW}]$ & $\mathrm{ATC}_{\text {firm }}[\mathrm{MW}]$ & $\mathrm{ATC}_{\text {nonfirm }}[\mathrm{MW}]$ \\
\hline 1 & 586 & 542 & 523 \\
\hline 2 & 586 & 538 & 517 \\
\hline 3 & 586 & 535 & 513 \\
\hline 4 & 586 & 527 & 501 \\
\hline 5 & 586 & 537 & 516 \\
\hline 6 & 586 & 537 & 515 \\
\hline 7 & 586 & 537 & 516 \\
\hline 8 & 586 & 537 & 515 \\
\hline 9 & 586 & 535 & 512 \\
\hline 10 & 586 & 533 & 510 \\
\hline 11 & 586 & 526 & 500 \\
\hline 12 & 586 & 526 & 500 \\
\hline 13 & 586 & 524 & 496 \\
\hline 14 & 586 & 528 & 502 \\
\hline 15 & 586 & 527 & 501 \\
\hline 16 & 586 & 524 & 496 \\
\hline 17 & 586 & 524 & 496 \\
\hline 18 & 586 & 523 & 495 \\
\hline 19 & 586 & 522 & 493 \\
\hline 20 & 586 & 515 & 484 \\
\hline 21 & 586 & 515 & 484 \\
\hline 22 & 586 & 510 & 476 \\
\hline 23 & 586 & 508 & 474 \\
\hline 24 & 586 & 508 & 473 \\
\hline 25 & 586 & 507 & 472 \\
\hline 26 & 586 & 506 & 470 \\
\hline 27 & 586 & 506 & 470 \\
\hline 28 & 586 & 504 & 467 \\
\hline 29 & 586 & 502 & 465 \\
\hline
\end{tabular}

different weights assigned to each tie-line, the selection of CBM result is performed similarly by referring to the abovementioned explanation of Pareto optimal front concept.

5.4. Results of Available Transfer Capability Incorporating Capacity Benefit Margin. In this section, the ATC results are obtained based on the four cases of power transfer as shown in Tables 7, 8, 9, and 10. The results of ATCs are obtained by considering the firm and nonfirm transfers of $\mathrm{CBM}_{\text {asg }}^{\text {Pareto }}$ located at the Pareto optimal front cluster as depicted in Table 6. Hence, for every case of power transfer, there are 29 results of ATC that give the flexibility to the ISO in choosing a suitable power transfer. It is noted that $\mathrm{CBM}_{\text {asg }}^{\text {Parto }}$ taken as a firm transfer contributes to slightly larger ATC values as compared to $\mathrm{CBM}_{\text {asg }}^{\text {Pareto }}$ which is taken as a nonfirm transfer. It can be concluded that, by incorporating the nonfirm transfer of $\mathrm{CBM}_{\mathrm{asg}}^{\text {Parto }}$ into ATC, there will be loss for certain amount of ATC in the power transfer contracts.
TABLE 8: Results of ATC from area 1 to area 3.

\begin{tabular}{|c|c|c|c|}
\hline EP run & $\mathrm{ATC}_{\text {base }}[\mathrm{MW}]$ & $\mathrm{ATC}_{\text {firm }}[\mathrm{MW}]$ & $\mathrm{ATC}_{\text {nonfirm }}[\mathrm{MW}]$ \\
\hline 1 & 271 & 258 & 220 \\
\hline 2 & 271 & 259 & 223 \\
\hline 3 & 271 & 260 & 227 \\
\hline 4 & 271 & 262 & 235 \\
\hline 5 & 271 & 259 & 224 \\
\hline 6 & 271 & 259 & 225 \\
\hline 7 & 271 & 259 & 225 \\
\hline 8 & 271 & 260 & 226 \\
\hline 9 & 271 & 260 & 227 \\
\hline 10 & 271 & 260 & 229 \\
\hline 11 & 271 & 262 & 236 \\
\hline 12 & 271 & 262 & 235 \\
\hline 13 & 271 & 262 & 236 \\
\hline 14 & 271 & 262 & 234 \\
\hline 15 & 271 & 262 & 234 \\
\hline 16 & 271 & 263 & 237 \\
\hline 17 & 271 & 263 & 238 \\
\hline 18 & 271 & 263 & 239 \\
\hline 19 & 271 & 264 & 242 \\
\hline 20 & 271 & 265 & 245 \\
\hline 21 & 271 & 265 & 248 \\
\hline 22 & 271 & 266 & 250 \\
\hline 23 & 271 & 266 & 251 \\
\hline 24 & 271 & 266 & 251 \\
\hline 25 & 271 & 267 & 253 \\
\hline 26 & 271 & 267 & 253 \\
\hline 27 & 271 & 267 & 254 \\
\hline 28 & 271 & 267 & 254 \\
\hline 29 & 271 & 268 & 260 \\
\hline
\end{tabular}

\section{Conclusion}

This paper has presented a new approach for calculating CBM taking into account tie-line reliability in the interconnected system. The proposed approach employs the ranking index in a Pareto-based EP technique that provides several choices of optimum CBM values. The effectiveness of the proposed method in determining the CBM has been tested on the modified IEEE-RTS79. The results presented have shown that the Pareto optimal front of CBMs is an inexpensive solution compared to the CBMs located at the non-Pareto optimal front. The other advantage associated with the proposed method is due to its ability in providing simultaneous optimal results of CBM, LOLE, and LOLE difference whereby all are located at the Pareto optimal front cluster. Hence, selection of the result does not rely solely on the value of CBM, but it is also concurrently based on the impact of total LOLE and total LOLE difference included under the ranking of Pareto optimal front. In short, ISO has the flexibility to select the CBM at the Pareto optimal front referring to the ranking index of total LOLE and total difference of LOLE. Finally, 
TABLE 9: Results of ATC from area 2 to area 1.

\begin{tabular}{|c|c|c|c|}
\hline EP run & $\mathrm{ATC}_{\text {base }}[\mathrm{MW}]$ & $\mathrm{ATC}_{\text {firm }}[\mathrm{MW}]$ & $\mathrm{ATC}_{\text {nonfirm }}[\mathrm{MW}]$ \\
\hline 1 & 1171 & 1115 & 1108 \\
\hline 2 & 1171 & 1110 & 1102 \\
\hline 3 & 1171 & 1106 & 1098 \\
\hline 4 & 1171 & 1096 & 1086 \\
\hline 5 & 1171 & 1109 & 1101 \\
\hline 6 & 1171 & 1108 & 1100 \\
\hline 7 & 1171 & 1109 & 1101 \\
\hline 8 & 1171 & 1108 & 1100 \\
\hline 9 & 1171 & 1106 & 1097 \\
\hline 10 & 1171 & 1104 & 1095 \\
\hline 11 & 1171 & 1095 & 1085 \\
\hline 12 & 1171 & 1095 & 1085 \\
\hline 13 & 1171 & 1091 & 1081 \\
\hline 14 & 1171 & 1097 & 1087 \\
\hline 15 & 1171 & 1096 & 1086 \\
\hline 16 & 1171 & 1091 & 1081 \\
\hline 17 & 1171 & 1091 & 1081 \\
\hline 18 & 1171 & 1090 & 1080 \\
\hline 19 & 1171 & 1088 & 1078 \\
\hline 20 & 1171 & 1080 & 1069 \\
\hline 21 & 1171 & 1080 & 1069 \\
\hline 22 & 1171 & 1073 & 1061 \\
\hline 23 & 1171 & 1071 & 1059 \\
\hline 24 & 1171 & 1070 & 1058 \\
\hline 25 & 1171 & 1069 & 1057 \\
\hline 26 & 1171 & 1067 & 1055 \\
\hline 27 & 1171 & 1067 & 1055 \\
\hline 28 & 1171 & 1065 & 1052 \\
\hline 29 & 1171 & 1063 & 1050 \\
\hline
\end{tabular}

CBM taken as a firm transfer yields to a relatively large value of ATC compared to CBM considered as nonfirm transfer.

\section{Conflict of Interests}

The authors declare that there is noconflict of interests regarding the publication of this paper.

\section{Acknowledgments}

This work was supported in part by the Research Management Institute (RMI), Universiti Teknologi MARA, Malaysia, under Grants 600-RMI/DANA 5/3/PSI (186/2013) and 600RMI/DANA 5/3/CFI (56/2013); the Ministry of Higher Education (MOHE), Malaysia, under Grant 600-RMI/ERGS5/3 (18/2012); and the Ministry of Science, Technology and Innovation (MOSTI), Malaysia, under Grant 03-01-01-SF0476.
TABLE 10: Results of ATC from area 3 to area 1.

\begin{tabular}{|c|c|c|c|}
\hline EP run & $\mathrm{ATC}_{\text {base }}[\mathrm{MW}]$ & $\mathrm{ATC}_{\text {firm }}[\mathrm{MW}]$ & $\mathrm{ATC}_{\text {nonfirm }}[\mathrm{MW}]$ \\
\hline 1 & 71 & 21.5 & 20 \\
\hline 2 & 71 & 24.5 & 23 \\
\hline 3 & 71 & 28.5 & 27 \\
\hline 4 & 71 & 36.5 & 35 \\
\hline 5 & 71 & 25.5 & 24 \\
\hline 6 & 71 & 26.5 & 25 \\
\hline 7 & 71 & 26.5 & 25 \\
\hline 8 & 71 & 27.5 & 26 \\
\hline 9 & 71 & 28.5 & 27 \\
\hline 10 & 71 & 30.5 & 29 \\
\hline 11 & 71 & 37.5 & 36 \\
\hline 12 & 71 & 36.5 & 35 \\
\hline 13 & 71 & 37.5 & 36 \\
\hline 14 & 71 & 35.5 & 34 \\
\hline 15 & 71 & 35.5 & 34 \\
\hline 16 & 71 & 38.5 & 37 \\
\hline 17 & 71 & 39.5 & 38 \\
\hline 18 & 71 & 40.5 & 39 \\
\hline 19 & 71 & 43.5 & 42 \\
\hline 20 & 71 & 46.5 & 45 \\
\hline 21 & 71 & 49.5 & 48 \\
\hline 22 & 71 & 51.5 & 50 \\
\hline 23 & 71 & 52.5 & 51 \\
\hline 24 & 71 & 52.5 & 51 \\
\hline 25 & 71 & 54.5 & 53 \\
\hline 26 & 71 & 54.5 & 53 \\
\hline 27 & 71 & 55.5 & 54 \\
\hline 28 & 71 & 55.5 & 54 \\
\hline 29 & 71 & 21.5 & 20 \\
\hline
\end{tabular}

\section{References}

[1] J. Zhang and A. Yokoyama, "Application of interline power flow controller to ATC enhancement by optimal power flow control," in Proceedings of the IEEE Lausanne POWERTECH, pp. 12261231, Lausanne, Switzerland, July 2007.

[2] M. M. Othman, A. Mohamed, and A. Hussain, "Determination of transmission reliability margin using parametric bootstrap technique," IEEE Transactions on Power Systems, vol. 23, no. 4, pp. 1689-1700, 2008.

[3] A. V. Gheorghe, M. Masera, M. Weijnen, and L. de Vries, Critical Infrastructures at Risk: Securing the European Electric Power System, Springer, 2006.

[4] Available Transfer Capability Definitions and Determination, NERC Report, North American Electric Reliability Council, Atlanta, Ga, USA, 1996.

[5] P. W. Sauer, "Technical challenges of computing available transfer capability (ATC) in electric power systems," in Proceedings 
of the 30th Annual Hawaii International Conference on System Sciences, pp. 589-593, January 1997.

[6] K. Thai and T. Tran, "Use of capacity benefit margin," NERC Standard MOD-006-0.1 and MOD-007-0, Tacoma Public Utilities, 2009.

[7] S. C. Savulescu, "A metric for quantifying the risk of blackout," in Proceedings of the IEEE PES Power Systems Conference and Exposition, pp. 1661-1664, October 2004.

[8] P. Kundur, J. Paserba, V. Ajjarapu et al., "Definition and classification of power system stability IEEE/CIGRE joint task force on stability terms and definitions," IEEE Transactions on Power Systems, vol. 19, no. 3, pp. 1387-1401, 2004.

[9] I. Dobson, S. Greene, R. Rajaraman et al., "Electric power transfer capability: concepts, applications, sensitivity and uncertainty," PSERC Publication 01-34, Power Systems Engineering Research Centre, Cornell University, New York, NY, USA, 2001.

[10] Y. Ou and C. Singh, "Assessment of available transfer capability and margins," IEEE Transactions on Power Systems, vol. 17, no. 2, pp. 463-468, 2002.

[11] Y. Liu, J. Wang, L. Zhang, and D. Zou, "Research on effect of renewable energy power generation on available transfer capability," Journal of Software, vol. 8, no. 4, pp. 802-808, 2013.

[12] H. Farahmand, M. Rashidinejad, A. Mousavi, A. A. Gharaveisi, M. R. Irving, and G. A. Taylor, "Hybrid mutation particle swarm optimization method for available transfer capability enhancement," International Journal of Electrical Power and Energy Systems, vol. 42, no. 1, pp. 240-249, 2012.

[13] T. Akbari, A. Rahimikian, and A. Kazemi, "A multi-stage stochastic transmission expansion planning method," Energy Conversion and Management, vol. 52, no. 8-9, pp. 2844-2853, 2011.

[14] R.-F. Sun, Y.-H. Song, and Y.-Z. Sun, "Capacity benefit margin assessment based on multi-area generation reliability exponential analytic model," IET Generation, Transmission and Distribution, vol. 2, no. 4, pp. 610-620, 2008.

[15] R. Rajathy, R. Gnanadass, K. Manivannan, and H. Kumar, "Computation of capacity benefit margin using differential evolution," International Journal of Computing Science and Mathematics, vol. 3, no. 3, pp. 275-287, 2010.

[16] M. M. Othman, A. Mohamed, and A. Hussain, "Available transfer capability assessment using evolutionary programming based capacity benefit margin," International Journal of Electrical Power and Energy Systems, vol. 28, no. 3, pp. 166-176, 2006.

[17] M. Ramezani, M. R. Haghifam, C. Singh, H. Seifi, and M. P. Moghaddam, "Determination of capacity benefit margin in multiarea power systems using particle swarm optimization," IEEE Transactions on Power Systems, vol. 24, no. 2, pp. 631-641, 2009.

[18] M. Ramezani, H. Falaghi, and C. Singh, "Capacity benefit margin evaluation in multi-area power systems including wind power generation using particle swarm optimization," in Wind Power Systems, Green Energy and Technology, pp. 105-123, Springer, Berlin, Germany, 2010.

[19] N. B. A. Rahman, M. M. Othman, I. Musirin, A. Mohamed, and A. Hussain, "Capacity Benefit Margin (CBM) assessment incorporating tie-line reliability," in Proceedings of the 4th International Power Engineering and Optimization Conference (PEOCO '10), pp. 337-344, Shah Alam Selangor, Malaysia, June 2010.
[20] D. Goldberg, Genetic Algorithm in Search, Optimization and Machine Learning, Addison-Wesley, New York, NY, USA, 1989.

[21] N. A. Salim, M. M. Othman, M. S. Serwan, M. FotuhiFiruzabad, A. Safdarian, and I. Musirin, "Determination of available transfer capability with implication of cascading collapse uncertainty," IET Generation, Transmission and Distribution, vol. 8, no. 4, pp. 705-715, 2014.

[22] P. M. Subcommittee, "IEEE reliability test system," IEEE Transactions on Power Apparatus and Systems, vol. 98, no. 6, pp. 20472054, 1979. 

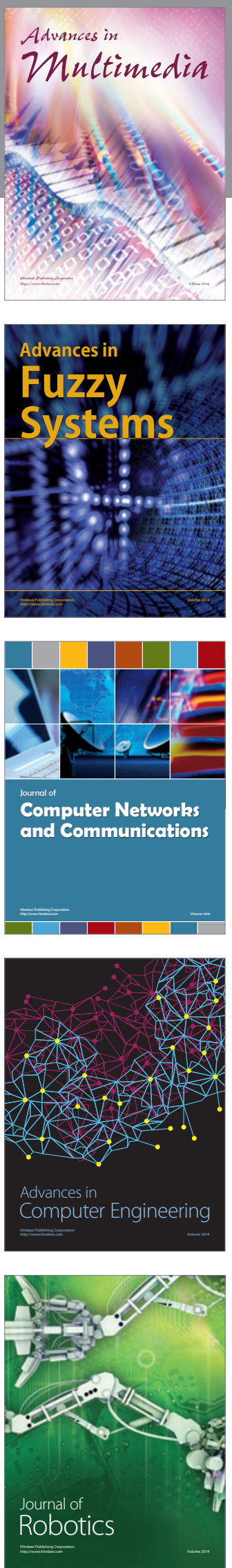

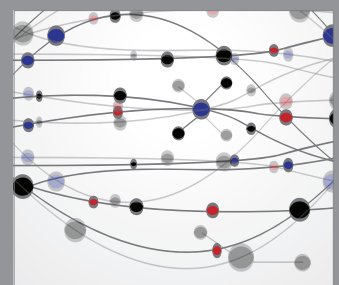

The Scientific World Journal
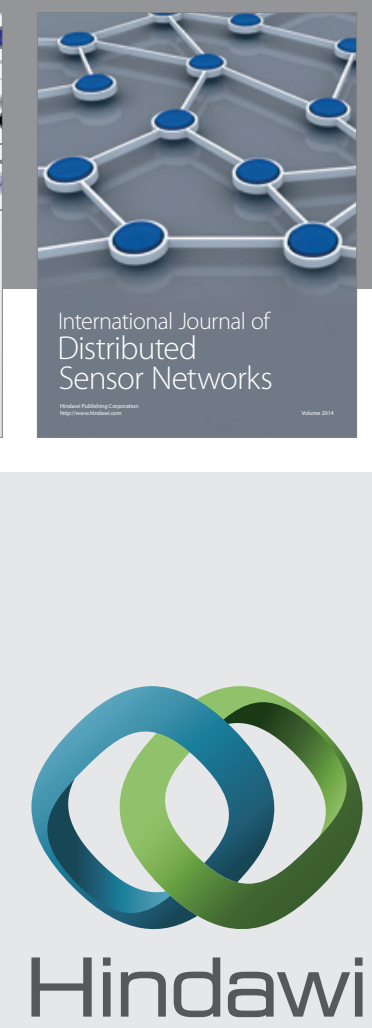

Submit your manuscripts at

http://www.hindawi.com
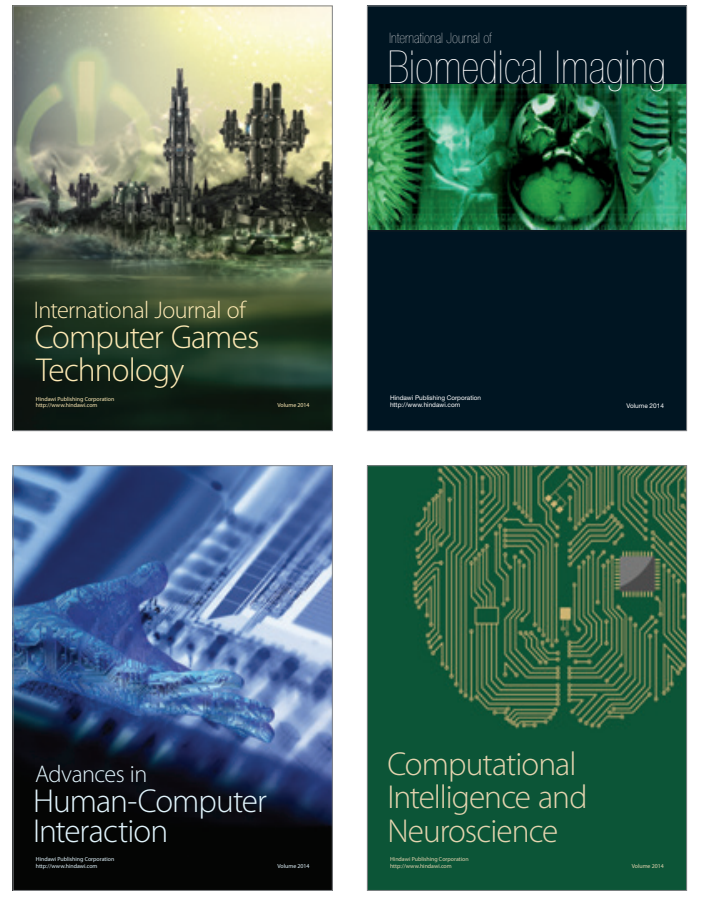
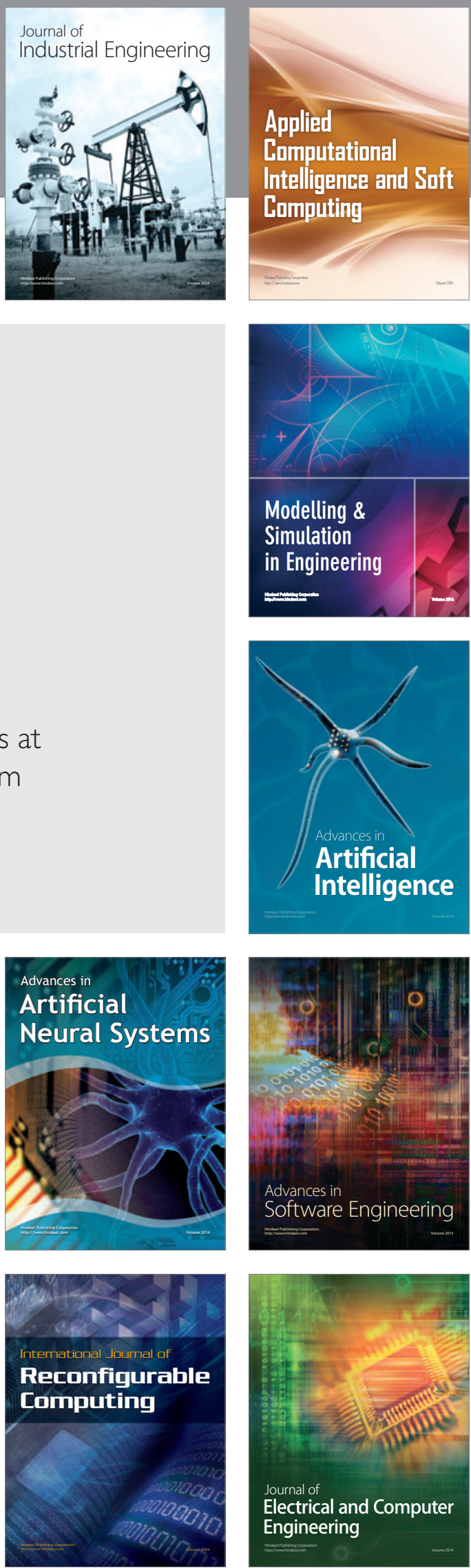